\title{
A Participação do Brasil nas Operações de Paz: passado, presente e futuro
}

\author{
Sergio Luiz Cruz Aguilar ${ }^{1}$
}

As operações de paz foram iniciadas em 1947 como uma forma da Organização das Nações Unidas (ONU) colocar em prática o sistema de segurança coletiva, parte de suas atribuições em relação à manutenção da paz e da segurança mundial. Nesses quase setenta anos 69 missões de paz foram realizadas², além de missões políticas especiais ${ }^{3}$ (UN, 2015).

A situação da ONU como principal agente "criador" de operações de paz mudou nas últimas duas décadas. Impulsionada principalmente pela crise que abateu a Organização na década de 1990 e, amparada no capítulo VIII de sua Carta, a ONU passou a dividir suas tarefas de manutenção da paz com organizações regionais e coalizões ad hoc de Estados (ou de interessados). ${ }^{4}$

Naquela mesma década, passou-se a trabalhar conceitualmente as operações de paz resultando em cinco categorias: a prevenção do conflito que implica na aplicação de medidas estruturais ou diplomáticas de modo a evitar que as tensões intraestados ou interestados se transformem em conflitos armados, podendo incluir o desdobramento

\footnotetext{
${ }^{1}$ Departamento de Sociologia e Antropologia e Programa de Pós-Graduação em Ciências Sociais da Faculdade de Filosofia e Ciências. UNESP - Campus Marília SP

${ }^{2}$ Conduzidas pelo Departamento de Operações de Manutenção da Paz - Department of Peacekeeping Operations (DPKO).

${ }^{3}$ Conduzidas pelo Departamento de Assuntos Políticos - Department of Political Affairs (DPA). Algumas dessas missões, por suas características foram conduzidas pelo DPKO.

${ }^{4}$ Tradução livre da expressão em inglês ad hoc coalitions of the willing.
}

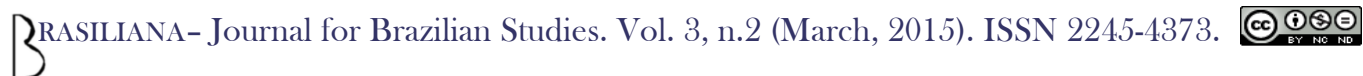


preventivo como o que ocorreu na FYROM em 19925; a promoção da paz (peacemaking) que inclui medidas após o início do conflito que visam levar as partes à negociação de acordos; a manutenção da paz (peacekeeping) destinada a preservar a paz, ainda que frágil, quando o conflito foi iniciado e auxiliar na implementação dos acordos obtidos (cessar-fogo, separação de forças, etc.); a imposição da paz (peace enforcement) que envolve a aplicação, com autorização do Conselho de Segurança das Nações Unidas (CSNU), de medidas coercitivas, incluindo o uso de forças militares; e a construção da paz (peacebuilding) que envolve medidas com o objetivo de reduzir o risco do retorno do conflito por meio do fortalecimento das capacidades nacionais para seu manejo em todos os níveis, e construir a paz e o desenvolvimento sustentáveis (UN, 2008).

As mudanças no sistema internacional pós Guerra Fria, a prevalência de guerras intraestatais sobre as internacionais, a diminuição do uso do poder de veto no CSNU, o alargamento conceitual do termo "segurança", a maior consciência sobre a responsabilidade dos Estados em prestar assistência, as repercussões negativas da forma do envolvimento da ONU nas guerras civis da Iugoslávia, Ruanda e Somália, o crescimento dos debates acerca dos direitos humanos e da proteção de pessoas ameaçadas pelo Estado ou por facções em luta, dentre outros, provocaram alterações nas operações de paz. Os mandatos passaram a utilizar maior uso da força do componente militar assim como um maior componente civil encarregado das ações de transição de uma situação de conflito para a construção da paz pós-conflito.

A partir do século XXI, tornaram-se comuns os mandatos mais robustos que autorizam o uso da força para proteção da população e/ou do próprio mandato, bem

\footnotetext{
${ }^{5}$ Desdobramento de uma força internacional na Antiga República Iugoslava da Macedônia - Former Yugoslavian Republic of Macedonia (FYROM) como parte da UNPROFOR, posteriormente transformada na UNPREDEP, para evitar que o conflito na Croácia e na Bósnia Herzegovina atingisse aquele país que acabava de se tornar independente. Sobre a UNPREDEP, ver AGUILAR, 2003.
}

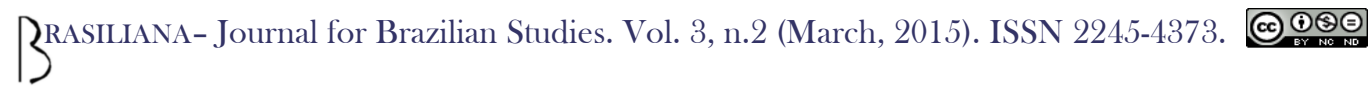


como a adoção de uma abordagem integrada para o desenvolvimento das chamadas operações multifuncionais ou complexas onde os componentes militares e policiais, responsáveis pela segurança, passaram a trabalhar com componentes civis responsáveis, principalmente, pela construção da paz.

Atualmente, dezesseis operações estão em andamento em quatro continentes (Haiti, Costa do Marfim, Libéria, Sahara Ocidental, Mali, República Democrática do Congo, República Centro Africana, Sudão, Darfur, Sudão do Sul, Índia e Paquistão, Chipre, Kosovo, Líbano, Síria e Oriente Médio) a um custo em torno de 7,06 bilhões de dólares para o período de 1 de julho de 2014 até 30 de junho de 2015 (UN, 2015). Em setembro de 2014 a ONU empregava 89.642 militares armados, 12.529 policiais e 1.741 observadores militares de 122 diferentes países. O número de funcionários civis era de 16.971, sendo 5.271 funcionários internacionais e 11.700 contratados locais. Com mais 1.813 pessoas do Programa de Voluntários das Nações Unidas o número total de pessoas empregadas em operações de paz era de 122.696 (UN, 2014).

O Brasil iniciou sua participação nas operações de paz em 1948, ao enviar militares para a Comissão Especial das Nações Unidas para os Bálcãs (UNSCOB), que operou na Grécia de 1947 a 1951. Desde então, o país participou de 53 operações de paz e missões políticas especiais sob a égide da ONU, de seis missões estabelecidas pela Organização dos Estados Americanos (OEA) e da Missão de Observadores Militares Equador-Peru, criada pelo Grupo Garante. A presença nas operações se deu com observadores militares, policiais, peritos eleitorais, especialistas em saúde, civis e tropas armadas, como em Suez, República Dominicana, Moçambique, Angola, Timor Leste, Haiti e Líbano.

O trabalho apresenta inicialmente como se deu a participação brasileira nas operações de paz e qual a situação atual da presença brasileira nas missões em

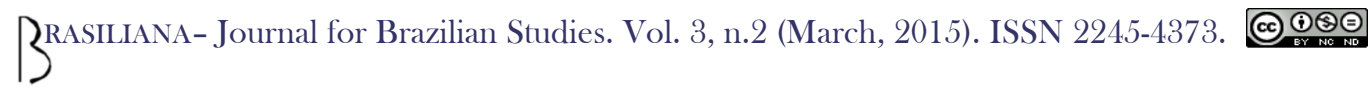


andamento para, em seguida, discutir algumas características, motivações e os desafios para o país em relação às tendências futuras dessas missões.

\section{Passado e Presente}

Em 21 de outubro de 1947, a Assembléia Geral das Nações Unidas (AGNU) estabeleceu a UNSCOB com a finalidade de monitorar a situação na fronteira entre a Grécia, em guerra civil, e a Albânia, Bulgária e Iugoslávia e cooperar com as autoridades regionais no problema dos refugiados. O Brasil inaugurou sua participação nesse tipo de missão enviando dois oficiais da Marinha e do Exército que lá permaneceram entre 1948 e 1949, além de diplomatas do Itamaraty (Fontoura, 1999).

A Primeira Sessão de Emergência da Assembléia Geral das Nações Unidas (AGNU) aprovou, em 1956, a formação da Força de Emergência das Nações Unidas (UNEF I) para assegurar e supervisionar o cessar fogo estabelecido após a crise no Canal de Suez e a retirada das forças armadas da França, Reino Unido e Israel do território egípcio. Após a retirada, deveria manter as condições pacíficas na área, posicionando-se numa zona tampão, a Linha de Demarcação do Armistício, entre as forças de Israel e Egito. O Brasil participou da UNEF I com um batalhão de infantaria, sendo o único país sul-americano a permanecer durante toda operação. Foram vinte contingentes que se revezaram entre 1957 a 1967, perfazendo um total de 6.300 homens que atuaram no Oriente Médio (Aguilar, 2005).

Quando a ONU criou a Força de Segurança das Nações Unidas na Nova Guiné Ocidental (UNSF), que atuou entre outubro de 1962 e abril de 1963, dois militares brasileiros que serviam na UNEF I foram enviados na missão avançada que precedeu o

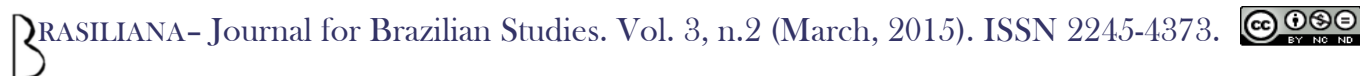


desdobramento da operação (AGUILAR, 2005). Ao ser criada a Missão de Observação da ONU no Iêmen (UNYOM), em julho de 1963, um oficial do Exército que se encontrava na UNEF I foi enviado como observador militar e ajudante do comandante da Missão (Brasil, 2011).

A partir de então, o Brasil participou com observadores militares da Missão do Representante do Secretário-Geral da ONU na República Dominicana (DOMREP), Missão de Observação das Nações Unidas na Índia-Paquistão (UNIPOM), Grupo de Observadores das Nações Unidas na América Central (ONUCA), Missão de Observação das Nações Unidas em El Salvador (ONUSAL), Missões de Verificação das Nações Unidas em Angola (UNAVEM I, II e III), Força de Proteção das Nações Unidas na exIugoslávia (UNPROFOR) ${ }^{6}$, Administração Transitória das Nações Unidas na Eslavônia Oriental (UNTAES), Missão de Observação das Nações Unidas na Península de Prevlaka (UNMOP), Força de Desdobramento Preventivo das Nações Unidas (UNPREDEP), Missão de Observação das Nações Unidas em Angola (MONUA), Missão de Observação das Nações Unidas em Uganda-Ruanda (UNOMUR), Missão de Observação das Nações Unidas na Libéria (UNOMIL), Operação das Nações Unidas em Moçambique (ONUMOZ), Missão de Verificação das Nações Unidas na Guatemala (MINUGUA), Missão das Nações Unidas no Timor Leste (UNAMET), Administração Transitória das Nações Unidas no Timor Leste (UNTAET), Missão de Assistência das Nações Unidas em Angola (UNMA), Missão das Nações Unidas na Costa do Marfim (MINUCI), Missão de Apoio das Nações Unidas no Timor Leste (UNMISET), Missão das Nações Unidas de Apoio à Paz no Sudão (UNMIS), Escritório das Nações Unidas no Timor Leste (UNOTIL), Missão Integrada das Nações Unidas no Timor Leste (UNMIT),

\footnotetext{
${ }^{6}$ Em 1995 foi desmembrada em UNCRO, UNPF e UNPREDEP (Aguilar, 2003).
}

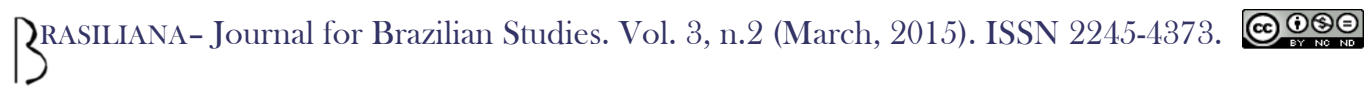


Missão das Nações Unidas na Etiópia e Eritréia (UNMEE), Escritório das Nações Unidas na África Ocidental (UNOWA), Missão das Nações Unidas no Nepal (UNMIN), Escritório de Apoio da ONU à Construção da Paz na Guiné Bissau (UNOGBIS), Missão das Nações Unidas na República Centro Africana e Chade (MINURCAT), Missão da ONU e União Africana em Darfur (UNAMID) e da Missão de Supervisão da ONU na Síria (UNSMIS).

Na Força de Manutenção de Paz das Nações Unidas em Chipre (UNFICYP), criada em 1964 para evitar a luta entre as comunidades greco-cipriota e turco-cipriota, dois militares brasileiros passaram a integrar o Batalhão Argentino, a partir de 1995.7

Após a UNEF I, a participação com tropas armadas aconteceu em mais sete ocasiões. Na Operação das Nações Unidas no Congo (ONUC) foi enviada uma unidade de transporte aéreo composta por pilotos de aviões, helicópteros e pessoal de apoio em terra num total de 179 militares da Aeronáutica que operaram entre julho de 1960 e junho de 1964. Com a rebelião armada na República Dominicana que eclodiu em 24 de abril de 1965, a OEA criou a Força Interamericana de Paz na República Dominicana (FIP). O Brasil enviou uma força de 1.450 homens, constituindo o Destacamento Brasileiro da Força Armada Interamericana (FAIBRÁS) que permaneceu naquele país até setembro de 1966. Com os revezamentos, participaram da operação cerca de três mil militares do Exército e do Corpo de Fuzileiros Navais da Marinha. Para a Operação das Nações Unidas em Moçambique (ONUMOZ), foi enviada uma Companhia de Infantaria Pára-quedista (entre julho e dezembro de 1994) com 170 militares (Aguilar, 2005).

Em Angola, o Brasil participou da UNAVEM III com um Batalhão de Infantaria (800 militares), uma Companhia de Engenharia (200 militares), dois Postos de Saúde

\footnotetext{
${ }^{7}$ A partir de 2005 passou a ser um militar.
}

$3^{R A S I L I A N A-~ J o u r n a l ~ f o r ~ B r a z i l i a n ~ S t u d i e s . ~ V o l . ~ 3, ~ n .2 ~(M a r c h, ~ 2015) . ~ I S S N ~ 2245-4373 . ~ @ \Theta \Theta \Theta ~}$ 
Avançados (40 militares) e cerca de 40 oficiais no Estado Maior do contingente militar. Com os revezamentos realizados, entre agosto de 1995 e julho de 1997, chegou-se a um efetivo total 4.174 militares (Aguilar, 2005).

Com a violência ocorrida no Timor Leste em setembro de 1999, a ONU desdobrou a Força Internacional do Timor Leste (INTERFET) para restaurar a segurança da qual o Brasil participou com um Pelotão de Polícia do Exército com 50 militares e um oficial superior comandante do contingente brasileiro. A tropa permaneceu integrando a força militar da UNTAET (entre 1999 e 2002), tendo sido aumentada para setenta militares. Com a criação da UNMISET, o Brasil manteve a tropa, aumentando o efetivo para 125 militares. ${ }^{8}$

Quando o Conselho de Segurança da ONU estabeleceu a Missão das Nações Unidas para a Estabilização no Haiti (MINUSTAH), em 2004, o Brasil enviou um batalhão de infantaria (BRABAT) que incorporou, posteriormente, um Grupamento Operativo de Fuzileiros Navais. Em 2005, o contingente brasileiro foi acrescido de uma Companhia de Engenharia. Com o terremoto de janeiro de 2010, o Brasil enviou mais um batalhão de infantaria que permaneceu no Haiti até 2013. Desde 2004, é responsável pelo comando da força militar e, consequentemente, fornece oficiais de Estado-Maior para compô-lo. ${ }^{9}$

O Brasil enviou policiais para a ONUSAL, UNAVEM II e III, UNPROFOR, UNTAES, MONUA, MINUGUA, UNAMET, UNMIS, ONUMOZ, UNTAET, UNMISET, UNOTIL, UNMIT, UNMIK, MINUSTAH, UNAMID e UNSMIS. Foram enviadas equipes médicas e/ou pessoal de saúde para a UNAVEM I, II e III, MONUA, UNOMUR,

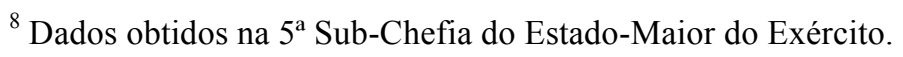

${ }^{9}$ Ibidem.
}

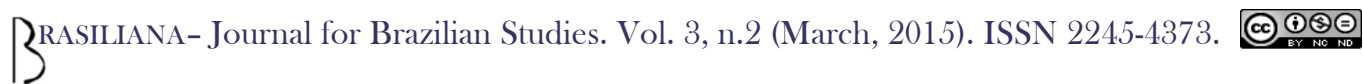


ONUMOZ, ONUSAL e UNPOS. O país também participou com observadores e/ou peritos eleitorais da ONUSAL, UNAVEM II, UNAMET, Autoridade Transitória das Nações Unidas no Camboja (UNTAC) e da Missão de Observação das Nações Unidas na África do Sul (UNOMSA) (Aguilar, 2005). ${ }^{10}$

Para a Comissão Especial das Nações Unidas no Iraque (UNSCOM), estabelecida ao final da Guerra do Golfo, o Brasil enviou militares peritos nas áreas de biologia, química e armamento (Revista Verde Oliva, 1998).

Em 2003, quando a ONU estabeleceu a Força Multinacional Interina de Emergência para operar na província de Ituri, na República Democrática do Congo, o Brasil enviou duas aeronaves C-130 Hércules com suas guarnições, incluindo pessoal de manutenção, comunicações e de saúde (Brasil, 2011).

No âmbito da OEA, esteve presente: na Missão da OEA no Suriname, entre 1991 e 1994, com peritos eleitorais e militares que participaram como assessores técnicos nos trabalhos de remoção de minas, além do fornecimento de equipamento especializado para aquela atividade (Soares, 1994); na OEA-DEMOC, estabelecida no Haiti em 1991, integrando o grupo de representantes com outros dez países americanos (Soares, 1994); na Missão de Assistência para Remoção de Minas na América Central (MARMINCA), na década de 1990, com militares do Exército e do Corpo de Fuzileiros Navais que prepararam peritos locais e supervisionaram as operações de desminagem com o acompanhamento do planejamento e execução dos trabalhos, incluindo aspectos de segurança (Aguilar, 2005); e na Missão de Assistência para a Remoção de Minas na

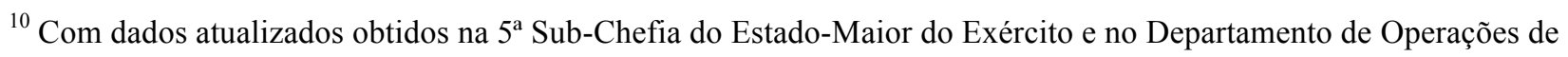
Manutenção da Paz da ONU.
}

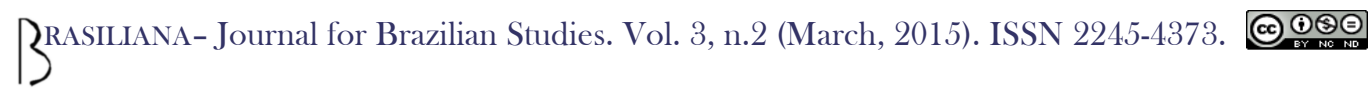


América do Sul (MARMINAS), que atuou na fronteira Equador-Peru entre 2003 e 2013 com militares supervisores de desminagem. ${ }^{11}$

Figura 1 - Missões com participação do Brasil encerrada ${ }^{12}$

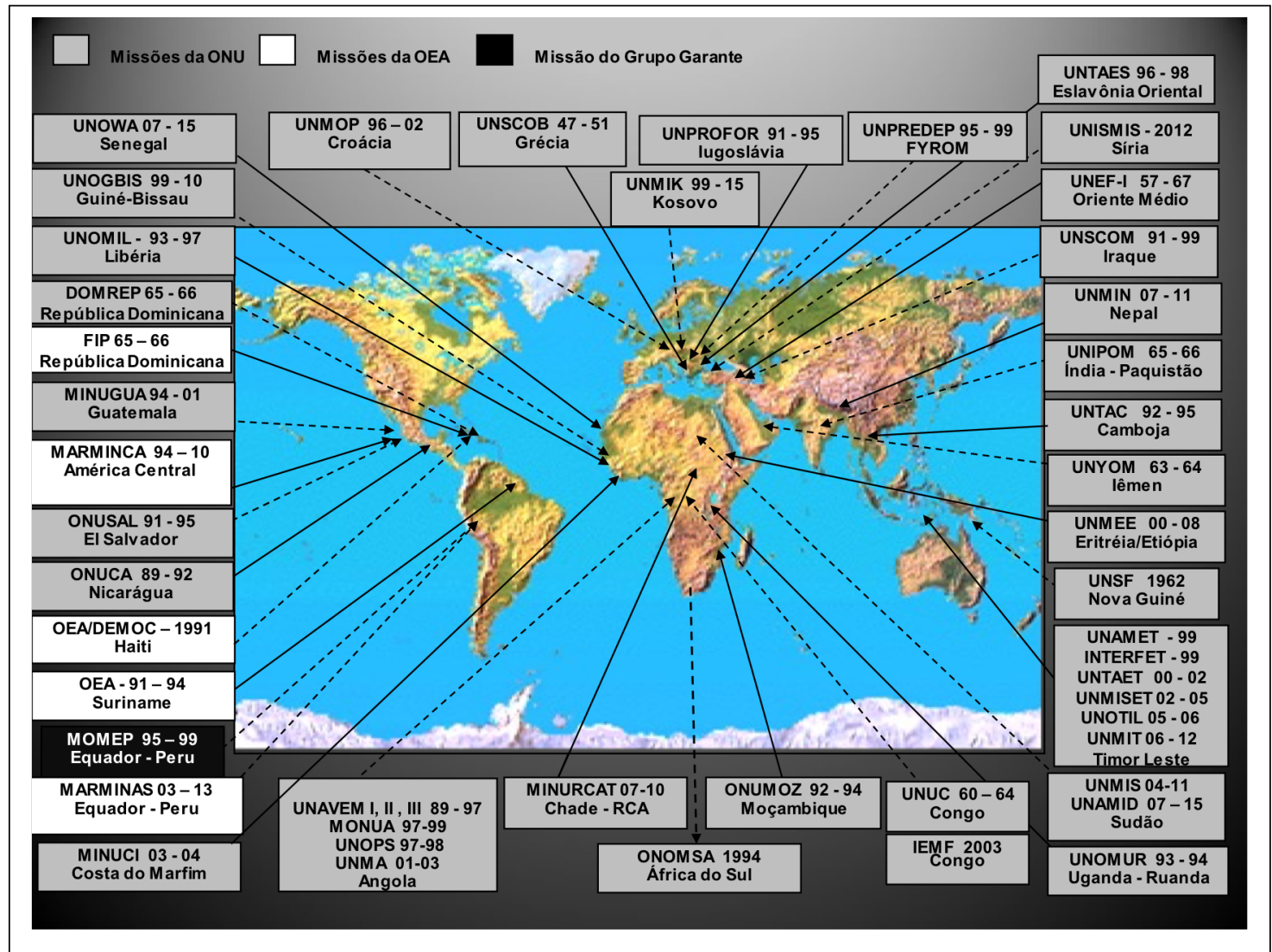

Em 1995, Peru e Equador voltaram à guerra por problemas fronteiriços na região da Cordilheira do Condor. Após um mês de conflito as negociações conduzidas pelos

\footnotetext{
${ }^{11}$ Dados obtidos na $5^{\text {a }}$ Sub-Chefia do Estado-Maior do Exército.

${ }^{12}$ Confeccionado pelo autor com base em dados da $5^{\text {a }}$ Sub-Chefia do Estado-Maior do Exército, UN/DPKO, Aguilar, 2005, Brasil, 2011 e Fontoura, 1999.
}

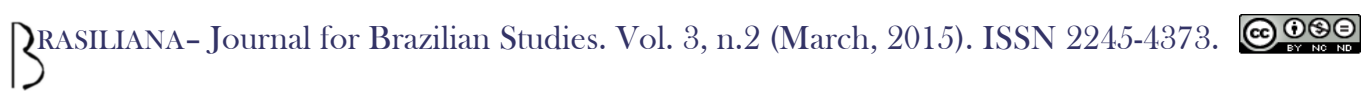


"Países Garantes" do Protocolo do Rio de Janeiro (Argentina, Brasil, Chile e EUA), levaram à assinatura da Declaração de Paz do Itamaraty, em 17 de fevereiro daquele ano, pelo qual os contendores aceitaram o estabelecimento da Missão de Observadores Militares Equador-Peru (MOMEP) a fim de monitorar o estabelecimento de uma área desmilitarizada. Após o acordo definitivo de paz assinado em outubro de 1998, que teve participação importante do governo brasileiro nas negociações, adicionaram-se à MOMEP as missões de verificação da retirada de minas e da colocação dos marcos fronteiriços. Em 17 de junho de 1999, a MOMEP foi encerrada. Ao longo de quatro anos, foram empregados 192 militares brasileiros sendo que, a partir de novembro de 1997, o Grupo de Apoio da Missão, que era encargo dos EUA, passou a ser multinacional e o Brasil foi encarregado de $60 \%$ da logística e do apoio de aviação (Moreno Jr., 2005).

Em dezembro de 2014, o Brasil participava de nove das 16 operações de paz em andamento e de uma missão política especial das Nações Unidas, além da missão de desminagem da OEA na Colômbia. Na Missão Multidimensional Integrada da ONU na República Centro Africana (MINUSCA), Missão para o Referendo no Saara Ocidental (MINURSO), Força de Segurança Interina no Abyei (UNISFA), Missão das Nações Unidas na Libéria (UNMIL) e na Operação das Nações Unidas na Costa do Marfim (UNOCI) havia a presença de observadores e oficiais de Estado-Maior. Na UNFYCIP, um oficial de Estado-Maior. Na Missão da ONU na República do Sudão do Sul (UNMISS), oficiais de Estado-Maior, oficiais de ligação e policiais militares. No Escritório Integrado da ONU de Construção da Paz na Guiné Bissau (UNIOGBIS), um oficial de Estado-Maior e policiais militares. Na Missão de Estabilização da ONU na República Democrática do Congo (MONUSCO), o Comandante do Componente Militar e seis oficiais de Estado-Maior. Na Força Interina da ONU no Líbano (UNIFIL), 261 militares da Marinha integrantes do componente naval e sete do Exército no Estado-

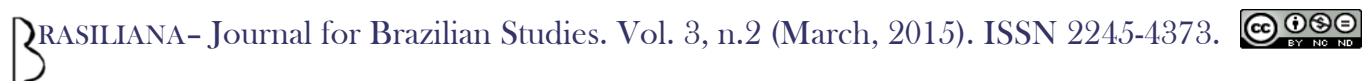


Maior da operação. Na MINUSTAH o efetivo do contingente brasileiro era de 1.414 militares do Exército, Marinha e Aeronáutica, do Paraguai, Bolívia e Peru integrantes do Batalhão Brasileiro, e policiais. No Grupo de Monitores Internacionais (GMI) na Colômbia, havia quatro supervisores de desminagem, sendo um médico. Além disso, o Brasil mantinha seis militares no DPKO em Nova Iorque e cinco oficiais generais em funções importantes relacionadas com as operações de paz: os comandantes dos componentes militares da MINUSTAH e da MONUSCO, o comandante da força naval da UNIFIL, o Diretor da Parceria Estratégica DPKO/DFS para a Manutenção da Paz e um membro do Painel Independente de Alto Nível sobres Operações de Paz, nomeado pelo SGNU em outubro de $2014 .{ }^{13}$

Figura 2 - Efetivo brasileiro em missões de paz - janeiro de 2015

\begin{tabular}{|l|c|c|c|c|c|c|}
\hline MISSÃO & Local & Efetivo & Exército & Marinha & Aeronáutica & Policiais \\
\hline UM/DPKO & Nova York-EUA & 6 & 4 & 2 & & \\
\hline MINUSTAH & Haiti & 1380 & 1079 & 247 & 35 & 19 \\
\hline UNIFIL & Líbano & 268 & 7 & 261 & & \\
\hline MINUSCA & Rep. Centro Africana & 5 & 3 & 2 & & \\
\hline MINURSO & Saara Ocidental & 10 & 7 & 1 & 2 & \\
\hline UNFYCIP & Chipre & 1 & 1 & & & \\
\hline UNMISS & Sudão do Sul & 13 & 7 & & 1 & 5 \\
\hline UNISFA & Sudão & 5 & 3 & 1 & 1 & \\
\hline MONUSCO & Rep. Dem. do Congo & 7 & 7 & & & \\
\hline UNOCI & Costa do Marfim & 7 & 4 & 2 & 1 & \\
\hline UNMIL & Libéria & 4 & 3 & 1 & & \\
\hline UNIOGBIS & Guiné-Bissau & 3 & & & & 1 \\
\hline GMI & Colômbia & 4 & 4 & & & 26 \\
\hline TOTAL & & 1713 & 1129 & 517 & 41 & \\
\hline
\end{tabular}

Fonte: $5^{\mathrm{a}}$ Sub-Chefia do EM do Exército

${ }^{13}$ Dados obtidos na $5^{\text {a }}$ Sub-Chefia do Estado-Maior do Exército.

$3^{R A S I L I A N A-~ J o u r n a l ~ f o r ~ B r a z i l i a n ~ S t u d i e s . ~ V o l . ~ 3, ~ n .2 ~(M a r c h, ~ 2015) . ~ I S S N ~ 2245-4373 . ~ @ @ ~}$ 


\section{Considerações sobre a Participação Brasileira}

A participação do Brasil em operações de paz é embasada em dispositivos legais como a Constituição Federal, a Política de Defesa Nacional, a Estratégia Nacional de Defesa e o Livro Branco de Defesa, leis específicas e nos diversos tratados internacionais que tratam da matéria e dos quais o país faz parte. A participação nessas operações é considerada como uma missão complementar ou subsidiária das forças armadas.

A decisão de participar de uma operação de paz é política, motivada por diversos fatores que vão desde a ajuda humanitária, desprovida de qualquer outra intenção, até a utilização dessas missões como forma de conquistar objetivos políticos.

O governo brasileiro tem enfatizado alguns princípios e fundamentos da participação brasileira. Os mais antigos se relacionam com a não-ingerência e a resolução pacífica dos conflitos e condicionam a presença brasileira nas operações estabelecidas ao estrito cumprimento das normas internacionais.

A partir do governo Lula, a postura da política externa foi atrelada ao conceito da não-indiferença. ${ }^{14}$ No seu discurso de posse, o então presidente definiu que a ação diplomática seria orientada por uma perspectiva humanista (Brasil, 2003). Em 2005, em pronunciamento na XXXV Assembléia Geral da OEA, o então Ministro das Relações Exteriores, Celso Amorim, disse que governo do Presidente Lula associava ao princípio básico da não-ingerência, uma atitude de não-indiferença, prestando "apoio e solidariedade ativos em situações de crise", sempre que solicitado (Brasil, 2005).

${ }^{14} \mathrm{O}$ conceito de não-indiferença surgiu no âmbito da União Africana (UA) em contraposição à cultura da nãointervenção que teria sido responsável pela inação da comunidade em alguns conflitos africanos da década de 1990 (MURITHI, 2009).

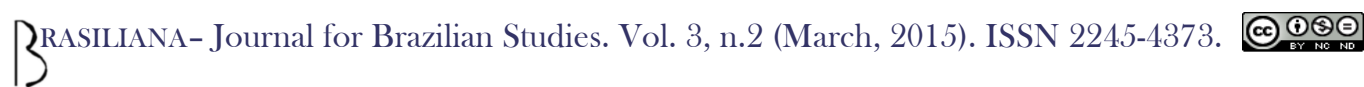


Utilizando a ação no Haiti, a partir de 2004, o protagonismo brasileiro naquele país foi relacionado com a chamada "diplomacia solidária" que seria a concepção e a aplicação da ação coletiva "feita por terceiros Estados intervenientes num conflito interno ou internacional, desprovidos de motivações decorrentes de seu interesse nacional e movidos unicamente por um dever de consciência" (Seitenfus, 2006). Dentro dessa concepção, o governo passou a enfatizar a importância do Brasil em participar dos esforços de desenvolver e promover justiça social no Haiti e nos demais países envolvidos em processos violentos.

No âmbito do sistema internacional, a ação brasileira no cenário internacional teria o objetivo de fortalecer o sistema multilateral de segurança, especialmente a ONU, dentro da ideia de que, como salientou Cervo (2008, p. 28), o fim do século XX deu “origem a uma ordem internacional, cujas regras transparentes, justas e respeitadas por todos seriam estabelecidas por meio da negociação multilateral". Neste sentido, as negociações multilaterais com os organismos internacionais (e com vários países e blocos) é uma forma de o Brasil garantir autonomia política nas suas relações internacionais, bem como aumentar a possibilidade da consecução de seus interesses. $\mathrm{O}$ fortalecimento do espaço multilateral serve para compensar as assimetrias presentes no sistema internacional ao mesmo tempo em que possibilita uma maior inserção do país.

A participação ocorre, também, por interesses particulares em relação às organizações internacionais. A partir da década de 1990, o aumento da presença brasileira nas missões de paz pode ser relacionado com o pleito por um assento permanente no CSNU. No caso da OEA, a presença nas missões de paz e de assistência pode ser relacionada com a intenção da política externa brasileira de fortalecer aquela organização e diminuir a influência que os norte-americanos exercem sobre ela.

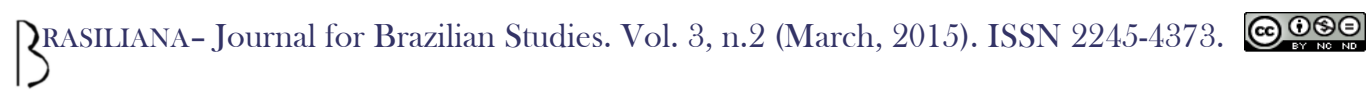


No caso da MOMEP, além do interesse brasileiro de colaborar com a manutenção da paz entre os países que compõem sua área prioritária de atuação, o entorno estratégico sul-americano, a participação se deu em cumprimento às obrigações geradas por um tratado internacional. O Protocolo do Rio de Janeiro, que constituiu o Grupo Garante do Acordo de Paz de 1941, estabeleceu obrigações para seus membros (Argentina, Brasil, Chile e Estados Unidos). Com o conflito Equador-Peru em 1995 o Brasil, como parte do Grupo Garante, assumiu essas obrigações. Mas foi além, responsabilizando-se por encargos importantes de logística e apoio de aviação e os custos decorrentes.

As afinidades com o país (ou países) em conflito são fatores que pesam na decisão de participar de determinadas operações. Os casos do envio de tropas armadas para as missões em Angola, Moçambique e Timor Leste, com certeza, se deram em decorrência da língua e do passado comum de colônias portuguesas. Esses casos podem indicar, também, o interesse brasileiro de projetar poder no âmbito da Comunidade dos Países de Língua Portuguesa (CPLP).

No mesmo sentido, há a relação com a região em que ocorre o conflito. A presença brasileira, bem como de diversos países sul-americanos na MINUSTAH, ocorreu, principalmente, por considerar que se tratava de um problema de segurança hemisférica.

A decisão de participar de uma operação de paz tem relação com a política interna do país. Durante o regime militar, o Brasil se afastou do CSNU por vinte anos. A redemocratização permitiu que a própria diplomacia do país se tornasse mais pró-ativa naquela organização internacional. Logicamente, o aumento da presença se relacionou com o aumento das missões estabelecidas a partir da década de 1990, mas a participação

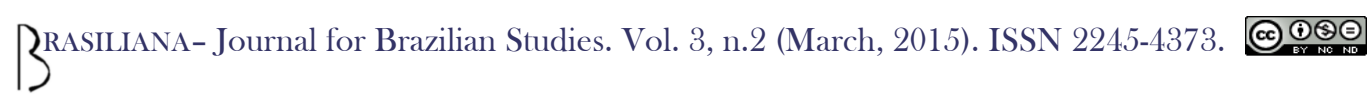


nas operações foi intensificada não apenas em número de missões como também em relação ao efetivo empregado.

A ausência de conflitos com seus vizinhos, de problemas fronteiriços ou reivindicações que possam gerar um processo conflitivo e a propensão pela resolução pacífica dos conflitos, tornaram-se argumentos utilizados tanto pelo governo como pelos militares brasileiros para maior contribuição aos esforços das organizações internacionais.

Para os militares, a participação das forças armadas nas operações de paz se relacionam com fatores importantes. Primeiro, a possibilidade de manter parte de seus efetivos adestrados em um ambiente de conflito. Segundo, a possibilidade de renovação do equipamento por meio das aquisições necessárias para dotar a tropa do melhor equipamento possível, já que parte desse custo é coberto pelo reembolso da ONU em decorrência do desgaste do material empregado. Terceiro, em relação aos vencimentos, uma vez que para os militares que integram uma operação de paz significa um aporte financeiro, pois os valores pagos quando em missão oficial no exterior superam os vencimentos recebidos no país. Quarto, colabora para a projeção do poder nacional no contexto internacional e permite o reconhecimento de outros países quanto ao nível profissional dos militares brasileiros, reforçando a estratégia da dissuasão. Quinto, atua como âncora da política externa brasileira quanto à solução pacífica de conflitos e desarmamento e fortalece os laços de confiança com os países amigos. Sexto, permite a melhoria do nível de cultura da tropa aumentando seu conhecimento sobre os povos e as áreas em que atua. Sétimo, possibilita a aquisição de conhecimentos para aprimorar a doutrina militar por conta da convivência com tropas de diferentes países.

Além disso, o aumento da presença nas missões de paz determinou a criação de uma estrutura de planejamento, preparo, apoio logístico, acompanhamento,

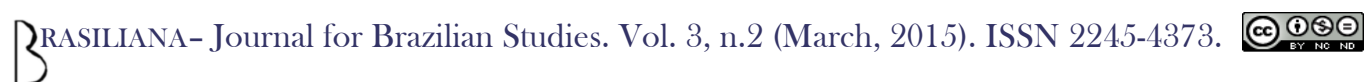


desmobilização, avaliação, pesquisa de doutrina, etc. Em 2005, foi criado o Centro de Instrução de Operações de Paz para apoiar a preparação de militares e tropas para as missões da ONU, transformado em 2010 no Centro Conjunto de Operações de Paz do Brasil (CCOPAB), composto por militares das três forças armadas (Brasil, 2010). O Ministério da Defesa (MD) e os comandos militares criaram seções específicas para tratar do tema como a Seção de Operações de Paz do Ministério da Defesa, a Divisão de Missões de Paz do Comando de Operações Terrestres (COTER) e a $5^{\text {a }}$ Sub-Chefia do Estado Maior do Exército, dentre outras.

Com relação ao tipo de operação, para o Brasil não há impedimento legal em participar de operações de imposição da paz, mas há uma tendência de evitá-las. No entanto, o país integrou a tropa armada da INTERFET, desdobrada no Timor Leste em setembro de 1999, que teve um mandato claro de imposição.

Percebe-se, também, que os governos brasileiros se mostram avessos a arranjos pré-estabelecidos, preferindo decidir caso a caso em quais missões e como participar, num exercício de decisão soberana de acordo com seus interesses. Mesmo fazendo parte do sistema de pronto emprego da ONU, a presença em alguma operação só ocorrerá após análise da pertinência pelos órgãos responsáveis e a aprovação do governo e do congresso nacional.

O Brasil tem utilizado as operações de paz para aumentar a cooperação coletiva sub-regional, especialmente entre os países do Mercosul. Por meio de acordos e memorandos de entendimentos, desde 1995, quando dois militares brasileiros passaram a integrar o contingente argentino em Chipre e militares argentinos fizeram parte das tropas brasileiras em Angola e no Timor Leste, o país tem incentivado essa prática no âmbito da ONU. Na MINUSTAH, militares paraguaios, bolivianos e peruanos atuaram com o contingente brasileiro.

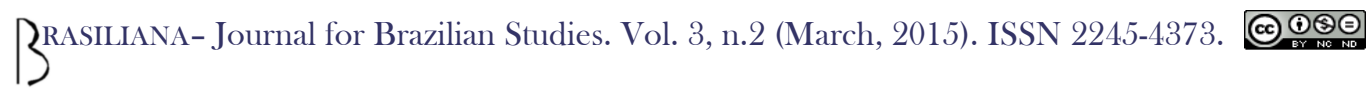


A ONU não estimula e tem colocado dificuldades para a implementação de tal cooperação, justificando problemas de comando e controle que podem ocorrer. Já o Brasil contra-argumenta que a presença conjunta de militares em contingentes de paz ajuda a atrair novos troop contributing countries para as operações de paz e utiliza como exemplo o caso da Bolívia que, através de um acordo bilateral, participou do Estado Maior da tropa brasileira com dois oficiais e, posteriormente, desdobrou uma companhia boliviana com 218 homens sob sua própria "bandeira" (Aguilar, 2011).

A MINUSTAH permitiu o estabelecimento de uma concertação sub-regional. A coordenação política entre os países do Mercosul se iniciou com várias reuniões com representantes dos governos da Argentina, Brasil, Chile e Uruguai. Em seguida, os governos desses quatro países estabeleceram um foro de discussões ad hoc com o objetivo de coordenar suas atividades no Haiti. O mecanismo de coordenação políticaestratégica recebeu a formulação 2 x n (o 2 indica a representação das áreas de defesa e de relações exteriores e o " $\mathrm{n}$ " significa o número de países que compõem o mecanismo). Iniciado em maio de 2005 como 2x4, com a participação de Argentina, Brasil, Chile e Uruguai por meio de reuniões de Vice-Ministros de Relações Exteriores e de Defesa (RESDAL, 2010), em agosto de 2005 incorporou representantes do Equador, Guatemala e Peru e, em fevereiro de 2007, Bolívia e Paraguai, passando a ser conhecido como 2x9.

\section{Considerações sobre o Futuro da Participação Brasileira}

As operações de paz são estabelecidas pelo $\mathrm{CSNU}^{15}$ e nele os membros permanentes têm uma prerrogativa maior na decisão de aprová-las ou não, com a utilização do poder de

\footnotetext{
${ }^{15}$ Embora haja a possibilidade da Assembléia Geral decidir pela criação de uma operação de paz, de acordo com a Resolução Uniting for Peace, de novembro de 1950, ela só foi utilizada quando a AGNU criou a UNEF I.
}

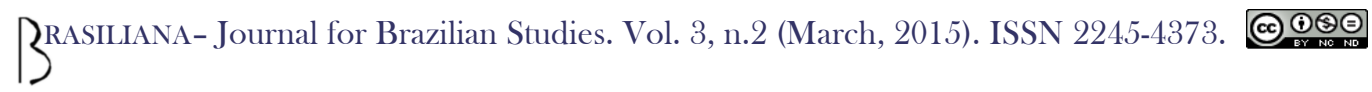


veto. No entanto, principalmente na atualidade, elas têm sido executadas pelos países do Sul. Em agosto de 2013, os dez maiores contribuintes eram responsáveis por 55,2\% do total de militares e policiais empregados nas operações. Enquanto isso, os membros permanentes do CSNU contribuíam com apenas 3,3\% do total. ${ }^{16}$ Em 2010, na MINUSTAH, do efetivo total de 11.984 militares e policiais pertencentes a 57 países, 5.385 pertenciam a nove países sul-americanos, correspondendo $45 \%$ do efetivo total da missão (Aguilar, 2011).

A porcentagem elevada de contingentes africanos envolvidos nas operações de paz naquela ocasião pode ser explicada pela quantidade delas em andamento na África (oito operações) e o maior envolvimento regional, ou seja, dos membros da União Africana. Tem relação, também, com o envolvimento dos EUA e dos europeus nas operações no Afeganistão e no Iraque, que demandaram que outros países assumissem responsabilidades nas operações conduzidas pela ONU. Mas tem relação com uma "divisão de trabalho" informal que foi estabelecida com os países mais desenvolvidos arcando com os maiores custos financeiros e os países em desenvolvimento assumindo o ônus operacional.

Apesar das discussões que se desenrolam na ONU com os maiores contribuintes financeiros exigindo a divisão desses encargos com os demais países e os maiores contribuintes com tropas pedindo uma maior participação dos mais desenvolvidos no terreno, o quadro atual se mostra interessante para ambos os grupos, incluindo o Brasil que, como a potência intermediária, aproveita essa situação para se mostrar mais atuante no campo da segurança internacional.

\footnotetext{
${ }^{16}$ Os maiores contribuintes com tropas, policiais e peritos em missão eram: Paquistão (8262), Bangladesh (7931), Índia (7858), Etiópia (6467), Nigéria (4880), Ruanda (4688) e Nepal (4606). Os membros permanentes contribuíam da seguinte forma: China (1775), França (955), Reino Unido (275), EUA (109) e Rússia (103) (UN, 2013).
}

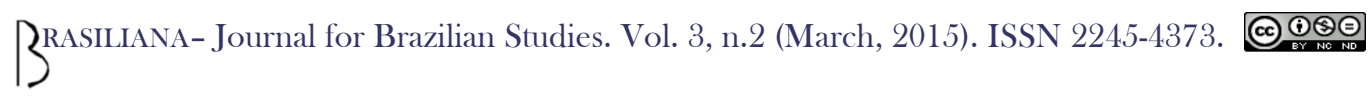


A participação do país nas operações de paz, como apresentado acima, se dá com o uso de meios militares e não-militares para projetar a política externa de modo a conquistar um papel mais importante no sistema internacional. Visa, portanto, obter uma maior inserção no sistema e ter um papel mais importante no processo decisório global de segurança. Para isso, é necessário ser mais atuante nas organizações, especialmente na ONU. Além disso, o fato de ser um dos países com maior produto interno bruto do mundo pode conduzir a maior cobrança tanto na participação efetiva com pessoal como em contribuições financeiras para as operações da paz.

O Brasil é um dos países que mais vezes integrou o CSNU como membro não permanente. Sendo o Conselho responsável pelo estabelecimento de uma operação de paz, a presença como membro do CSNU seria um fator de incentivo para que o país integre as operações sobre as quais participou das decisões e ajudou a aprovar. O objetivo de conquistar um assento permanente no CSNU implicaria também na necessidade de aumentar a participação nas operações. O protagonismo na MINUSTAH (Haiti) e na UNIFIL (Líbano) pode indicar a disposição por maior participação com tropas armadas.

As alterações dos mandatos e as tendências atuais de estabelecimento e condução das operações de paz podem ter algumas implicações para o Brasil. A possibilidade de maior uso da força nos mandatos indica a necessidade dos que fornecem tropas em aceitar o ônus político, financeiro e até humano de realizar operações ofensivas contra um Estado ou facções em luta.

O exemplo da MONUSCO na RDC pode indicar uma disposição do CSNU de, quando necessário, alterar o mandato dotando a operação de paz de poder de intervenção, autorizando o uso da força contra determinadas facções, atuando com mais pragmatismo e flexibilidade quando ocorrerem alterações nos conflitos (ver UN,

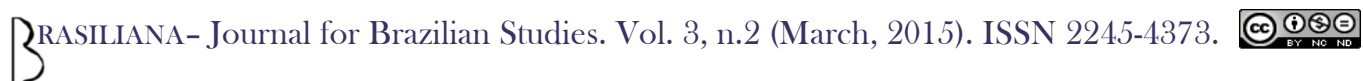


S/RES/2098, 2013). Pode ser, ainda, uma indicação de que o CSNU não pretende mais deixar de agir por condicionar suas decisões aos pilares básicos que conduziram as operações de paz desde a UNEF. ${ }^{17}$

Com a maior flexibilidade que permite a aprovação (ou transformação) de um mandato impositivo ou mais intrusivo no Estado hospedeiro, os Estados contribuintes com tropas devem se manter em condições de, caso necessário e rapidamente, adaptar suas tropas para usar a força além da situação inicial de legitima defesa. Ao participar de operações onde ocorrem mudanças rápidas no ambiente e nos mandatos, as tropas brasileiras podem se envolver em situações cujo resultado pode trazer prejuízo para a imagem do país perante a sociedade internacional. Se há a busca de ganhos políticos com a presença numa operação, problemas ou "fracassos" comprometeriam a conquista dos objetivos maiores da política exterior do Brasil.

Algumas operações têm a proteção de civis como uma das atividades para cumprimento do mandato. Em outras, a proteção é o objetivo principal da operação, podendo necessitar de ações ofensivas, aumentando a possibilidade de perda de vidas (das tropas da ONU, dos grupos envolvidos e de civis do Estado hospedeiro) e danos à propriedade. Ao enviar uma força armada para integrar esse tipo de operação deve-se observar a necessidade de dotar essa força de capacidade para realizar as atividades previstas. Se o Brasil integra uma operação com mandato mais intrusivo, deve acompanhar e influenciar na confecção das diretrizes e regras de engajamento de modo que determinem claramente o significado de "proteger civis" ou de "todos os meios necessários" e qual sua dimensão no espaço. Isso para evitar, ou ao menos diminuir a

\footnotetext{
${ }^{17}$ A Resolução que criou a UNEF I definiu os pilares que balizaram as operações de paz seguintes: uso da força limitado à autodefesa, consenso e cooperação das partes em conflito, comando e controle da ONU, composição multinacional da operação, neutralidade em relação às forças armadas rivais e imparcialidade política da ONU nas suas relações com os Estados envolvidos no conflito (UN, A/3943, 1958).
}

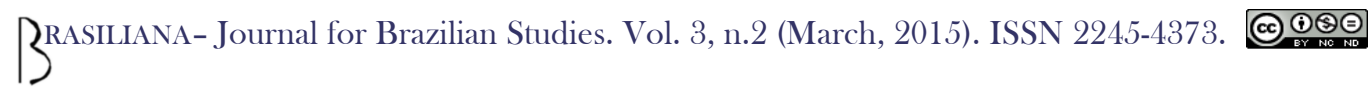


possibilidade de implicações jurídicas para a tropa, tanto no sentido de não conseguir cumprir a missão de "proteger" como no caso do uso da força excessiva para poder cumprir essa missão, com conseqüências para o país. O não cumprimento da obrigação de "garantir a segurança" em Srebrenica, na Bósnia, pelo batalhão holandês da UNPROFOR, em 1995, resultou em ações jurídicas nos tribunais holandeses (Nollkaemper, 2011; Brockman-Hawe, 2011). Já o afã de estabelecer um ambiente seguro na Libéria, na década de 1990, utilizando "todos os meios necessários" resultou no uso excessivo da força pela Comunidade Econômica dos Estados da África Ocidental (CEDEAO) e o cometimento de abusos contra os direitos humanos (Holt; Berckman, 2006).

A participação de uma operação com esse tipo de mandato indica a necessidade de uma análise mais cuidadosa da característica e composição da tropa, seu armamento e equipamento; do terreno em que vai atuar; das probabilidades e natureza das oposições armadas à tropa; do papel dos demais componentes e do impacto de suas ações nas operações militares; e da logística necessária, dentre outras. Alterações no mandato para maior intrusão, ou seja, o uso a força para proteger o processo de paz ou civis, dependendo da capacidade das partes em conflito, pode conduzir a uma estruturação de combate do componente militar da força de paz, incluindo carros de combate, artilharia, aviões e helicópteros de ataque, diferente de uma configuração levemente armada. Isso implica em uma análise mais profunda e cuidadosa, tanto durante o processo decisório sobre a participação, como durante o planejamento e a execução no terreno pela tropa.

Os mandatos mais impositivos das operações de paz indicam maior possibilidade das tropas se engajarem em operações de combate. Havendo dificuldades de conseguir contribuintes para essas operações, pode haver uma pressão para que os membros com

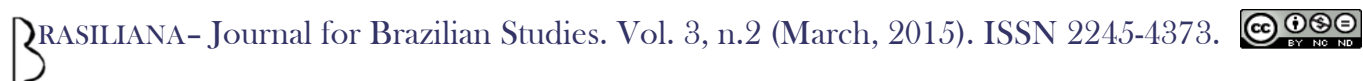


maior poder no processo decisório (CSNU) participem com maior efetivo nas operações desse tipo. Ou seja, maior poder político na ONU corresponderia à maior disposição de engajamento nas operações de paz.

Principalmente nas operações com mandato mais impositivo, avulta de importância o binômio meios necessários e disposição para alcançar o objetivo. Mas, capacidade e disposição da tropa de um Estado contribuinte não indica que estará imune a baixas ou ao fracasso caso a operação como um todo deixe a desejar, o que leva à necessidade do acompanhamento sobre a evolução da situação no terreno e suas decorrências e reforça a necessidade do uso da inteligência e de "novas" tecnologias.

A ONU trata como tema sensível a utilização de inteligência, operações psicológicas e as chamadas "novas tecnologias" pelas operações de paz. As informações sobre a situação no terreno sempre ficaram centradas principalmente nos observadores militares. Algumas tropas usam a inteligência em proveito próprio, mas não há o estabelecimento de um sistema de inteligência integrado. A autorização para o uso de VANTs no Congo e as discussões sobre o tema no painel nomeado pelo Secretário Geral da $\mathrm{ONU}^{18}$, indicam que a Organização tende a usar esses meios em prol das operações.

A característica de admitir o uso da força apenas em defesa própria choca-se com a característica natural dos militares que são treinados para usar a força. Em decorrência, os componentes militares enviados para as operações passam por uma adaptação no modo de atuar. Ao invés de se engajar em combates, as forças militares devem guarnecer zonas desmilitarizadas ou proteger os civis das ações das facções em luta. No caso do Brasil, a utilização das forças armadas nas missões chamadas subsidiárias dentro do país, diminui o problema de adaptação para essas atividades.

\footnotetext{
${ }^{18}$ O Painel Independente de Alto Nível sobre Operações de Paz da ONU foi constituído ém outubro de 2014 (Brasil, MRE, 2014).
}

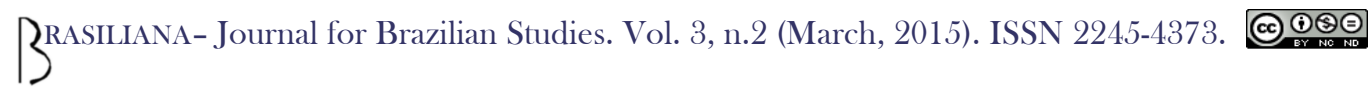


A tendência atual de alterações nos mandatos e da realização de ações ofensivas indica a necessidade de que a tropa a ser enviada receba o treinamento para operações de não guerra e de guerra, e para uma transição rápida de uma forma para outra. $\mathrm{O}$ inverso também pode acontecer. A tropa brasileira na MINUSTAH iniciou a operação com um mandato impositivo, empreendendo ações armadas para pacificar várias favelas da capital haitiana para, em seguida, junto com a manutenção da segurança, realizar o que se denomina no Brasil "ações cívico-sociais". Com o terremoto de 2010, a tropa teve que fazer uma rápida adaptação focando na assistência humanitária.

Outra questão diz respeito ao tempo de desdobramento. A ONU estabeleceu o sistema de forças de pronto emprego - UN Stand-By Arrangements System (UNSAS) do qual o Brasil participa. No entanto, a rapidez do desdobramento das forças ainda tem relação com o processo decisório de cada país. No caso do Brasil, por força legal, deve haver a autorização do Congresso. No caso do envio de tropas para Moçambique e Angola o processo decisório brasileiro foi demorado. No caso do Timor Leste (1999), do Haiti (2004) e do terremoto de 2010 naquele país o processo foi rápido. Como cada caso é um caso, a articulação do Executivo com o Legislativo e com os ministros da área econômica serão fundamentais para a decisão e a velocidade em que futuros desdobramentos ocorrerão.

As operações de construção da paz têm a característica de nascerem com uma perspectiva de longo prazo. Atuar nas causas dos conflitos, reconstruir instituições e infra-estrutura, criar e consolidar mecanismos de direitos humanos, etc., indicam a possibilidade de permanência mais longa da operação no país hospedeiro. A MINUSTAH está completando dez anos no Haiti. Ao se envolver nesse tipo de operação, o Brasil deve ter a consciência que sua permanência poderá ser necessária por um longo período. Logo, deve haver a predisposição de governo e sociedade em relação

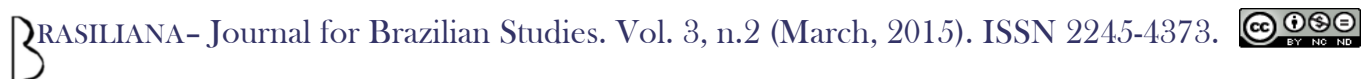


a essa permanência e, em decorrência, dos recursos gastos na manutenção de suas tropas na operação.

O processo de envio de tropas adotado pelo Brasil resulta na situação em que, a cada seis meses, uma tropa está desdobrada na missão, uma em desmobilização, outra em treinamento e uma quarta se organizando. A possibilidade de atuar em diferentes operações ao mesmo tempo e com diferentes mandatos pode ter como consequência a necessidade de preparações diferentes, ou parte da preparação direcionada para as diferentes atividades que a tropa poderá realizar. Implica, ainda, em aumentar a estrutura de preparo, emprego, logística e de acompanhamento das missões, com os custos decorrentes.

A maior presença brasileira na agenda global de segurança pode implicar, também, no aumento da participação como forma de auxilio à ONU nos processos político-diplomáticos (peacemaking). Os esforços diplomáticos, que normalmente ocorrem antes do estabelecimento de uma operação de paz, mas também paralelo a elas, envolvem negociações que buscam o consenso das partes envolvidas no conflito. $\mathrm{O}$ Brasil tem uma tradição de utilizar meios pacíficos para solução de controvérsias e sua diplomacia é respeitada internacionalmente. Dessa forma, o país pode vir a ser requisitado a auxiliar os processos de prevenção e de resolução de conflitos fornecendo especialistas em mediação e negociação. Além do expertise nesse campo, é necessário o íntimo conhecimento do conflito, incluindo suas causas, a história e a cultura de seu povo, e as necessidades do (s) Estado (s) onde o mesmo se desenrola e da sua população. Ou seja, a maior participação do Brasil implica, também, na necessidade de fomentar a formação de especialistas, não só no Itamarati como na sociedade civil, que possam atuar como representantes do Estado e/ou ocupando posições seniores no staff das operações de paz e dos órgãos da ONU relacionados com elas.

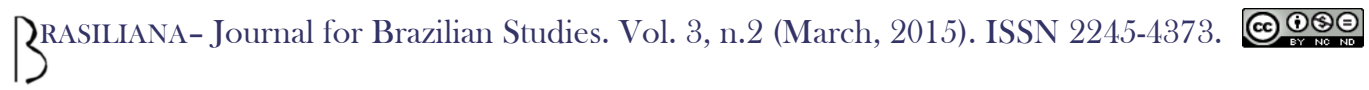




\section{Conclusão}

O Brasil tem tido uma participação ativa nos empreendimentos pela manutenção da paz dos organismos internacionais, se fazendo presente em 53 operações de paz e missões políticas especiais da ONU. Em janeiro de 2015 participava de nove das dezesseis operações de paz em andamento e de uma operação política especial da ONU, além da missão de desminagem da OEA na Colômbia com um efetivo de 1.687 militares e 26 policiais. Na maior parte das operações a presença do país se deu com observadores militares. Mas, em decorrência do envio de tropas para algumas operações e, especialmente da presença no Haiti por quase uma década, nos 66 anos de participação em forças internacionais de paz o país enviou para o exterior mais de 45 mil militares e policiais.

O conhecimento acumulado nas missões em que o país esteve presente permitiu a criação de um processo de seleção, preparo e envio de contingentes militares e policiais. No entanto, o país ainda não tem uma política de fomento para que civis especialistas se preparem e sejam enviados para desempenhar as diversas funções que as operações de construção da paz atuais exigem.

A participação em operações de manutenção da paz tem relação com projeção de poder, consecução de objetivos da política externa, reforço da estratégia da dissuasão, fortalecimento dos laços de confiança com os países amigos, prestação de ajuda humanitária sob o prisma da não indiferença, presença nos entornos estratégicos prioritários para a segurança nacional (América do Sul e África Atlântica) e auxilio a maior inserção do país no poder decisório internacional de segurança, fortalecendo o

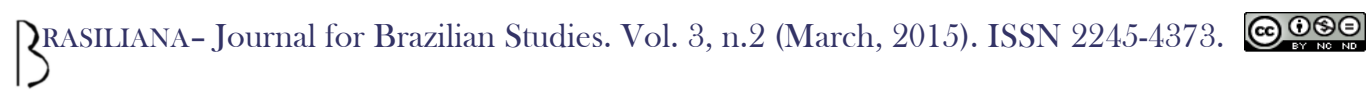


espaço multilateral como forma de compensar as assimetrias presentes no sistema internacional, dentre outras.

A participação brasileira deve continuar no patamar em que se encontra com observadores militares, policiais, equipes de saúde e de desminagem e especialistas civis, principalmente observadores eleitorais. Logicamente, o desdobramento de tropas armadas é condicionado às operações (criadas ou em andamento) e aos demais contribuintes. Acreditamos que o Brasil continuará propenso a participar pelo menos com um batalhão (situação do início da MINUSTAH em 2004) podendo chegar a dois batalhões e outros tipos de tropas (situação entre 2011 e 2013 quando o Brasil manteve dois batalhões de Infantaria e uma companhia de engenharia no Haiti mais o componente naval no Líbano).

A maior participação brasileira na agenda de segurança internacional exigirá discussões sobre temas como: o engajamento em operações de imposição da paz; a participação em operações com mandato mais intrusivo, incluindo a possibilidade de se engajar em combate contra facões em luta; a flexibilidade estrutural e a adaptabilidade dos componentes para lidarem com as alterações dos mandatos e fazerem a transição de operações de não guerra para operações de combate, e vice-versa, dentro de uma mesma missão de paz; a capacidade de desdobrar efetivos em curto espaço de tempo, com a aceleração do processo decisório interno; a disposição de empregar mais recursos, humanos e financeiros, fora do país; a possibilidade de se engajar em operações com perspectiva de longo prazo e o desgaste político decorrente; a disposição de empregar recursos para estruturas e processos no interior do país para possibilitar a maior presença nas operações, dentre outros.

Finalmente, entendemos que a maior presença no processo decisório de segurança global conduz a necessidade de um esforço em encontrar formas brasileiras 
para maior participação no planejamento estratégico da ONU para as operações de paz. Como o país não figura entre os maiores contribuintes com tropas, nem entre os maiores contribuintes financeiros para as operações, uma idéia seria a construção de parcerias com grupos de países diferentes que comungam dos mesmos interesses nesse campo. Internamente, indica a necessidade de maior diálogo com os envolvidos no governo, congresso e na sociedade em geral, sobre as aspirações brasileiras e como construir uma política de Estado nesse sentido.

\section{Referências Bibliográficas}

Aguilar, Sérgio Luiz Cruz. 2003. A Guerra da Iugoslávia: uma década de crises nos Bálcãs. São Paulo: Usina do Livro.

. 2011. A Participação Sul-Americana nas Operações de Paz da ONU: Algumas Considerações. Security and Defense Studies Review, v. 12, fall-winter 2011. Washington: CHDS, p. 99-116.

. (Org.). 2005. Brasil em missões de paz. São Paulo: Usina do Livro.

Brasil. 2011. MB. Diretoria do Patrimônio Histórico e Documentação. Brasil: 60 years of peacekeeping operations. Rio de Janeiro: Serviço de Documentação da Marinha.

2005. MRE. Discurso pronunciado pelo Ministro Celso Amorim por ocasião da XXXV Assembléia Geral da Organização dos Estados Americanos - "Tornando realidade os benefícios da Democracia". Fort Lauderdale - EUA, 6 jun. 2005. Disponível em: $<$ http://www.itamaraty.gov.br/sala-de-imprensa/discursos-artigos-entrevistas-e-outrascomunicacoes/ministro-estado-relacoes-exteriores/discurso-pronunciado-pelo-ministrocelso-amorim>. Acesso em: 15 jan. 2012.

. 2014. MRE. High-level Independent Panel on UN Peace Operations. Terms of Reference. Brasília, jan., mimeo. 2010. Portaria Nr 952 MD. Brasília, 15 jun..

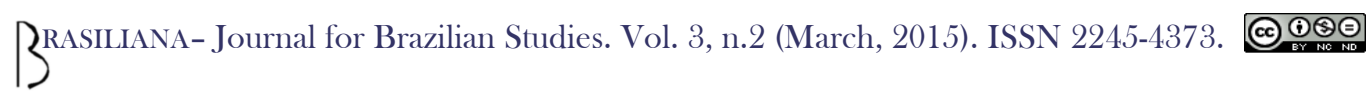


2003. Presidência da República. Discursos do Presidente. Brasília: Secretaria de Comunicação e Gestão Estratégica.

Brockman-Hawe, Benjamin E. 2011. Questioning the UN's Immunity in the Dutch Courts: Unresolved Issues in the Mothers of Srebrenica Litigation. University Global Study of Law Review, Washington, n. 727, p. 727-748. Disponível em: $<$ http://digitalcommons.law.wustl.edu/globalstudies/vol10/iss4/3>. Acesso em: 12 abr. 2013.

Cervo, Amado Luiz. 2008. Inserção internacional: formação dos conceitos brasileiros. São Paulo: Saraiva.

Fontoura, Paulo R. C. Tarrisse da. 1999. O Brasil e as Operações de Manutenção da Paz das Nações Unidas. Brasília: Instituto Rio Branco/FUNAG/Centro de Estudos Estratégicos.

Holt, Victoria K.; Berkman, Tobias C. 2006. The Impossible Mandate? Military preparedness, the responsibility to protect and modern peace operations. Washington: The Henry L. Stimson Center.

Moreno Jr., Nilton José Batista. 2005. A participação do Brasil no processo de paz Equador-Peru. In: Aguilar, Sérgio Luiz Cruz (Org.). Brasil em missões de paz. São Paulo: Usina do Livro, p. 125-142.

Murithi, Tim. 2009. The African Union's Transition from Non-Intervention to NonIndifference: an ad hoc Approach to the Responsibility to Protect? Reliefweb. New York. Disponível em: <http://library.fes.de/pdf-files/ipg/ipg-2009-1/08_a_ murithi_us.pdf>. Acesso em 30 out. 2011.

Nollkaemper, André. 2011. Dual attribution: liability of the Netherlands for conduct of Dutchbat in Srebrenica. Amsterdam Center for International Law, Research Paper n. 2011-11, Amsterdan: ACIL.

Resdal. 2010. Atlas Comparativo de la Defensa en America Latina y Caribe. Edición 2010. Especial Haiti. Buenos Aires: Resdal.

Revista Verde Oliva. 1998. a. XXVI, n. 163. Brasília, Set/Out.

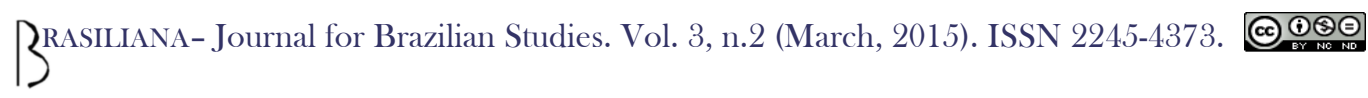


Seitenfus, Ricardo. 2006. Elementos para uma diplomacia solidária: a crise haitiana e os desafios da ordem internacional contemporânea. Carta Internacional, v. 1, n. 1, mar.

Soares, João Clemente Baena. 1994. Sintese de uma Gestão 1984-1994. Washington: OEA/OAS.

UN. A/3943. 1958. Summary Study of the Experience Derived from the Establishment and Operation of the Force: report of the Secretary-General. New York, 9 Oct..

. 2014. DPKO. Peacekeeping Fact Sheet. New York, 30 Sep. Disponível em: $<$ http://www.un.org/ en/peacekeeping/archieve/2014/bnote0914.pdf >. Acesso em: 20 dez. 2014.

. 2015. DPKO. Peacekeeping Fact Sheet. Disponível em: <http://www.un.org/en/ peacekeeping/resources/statistics/factsheet.shtml>. Acesso em: 02 jan. 2015.

. 2013. Monthly Summary of Contributors. New York, 31 Aug. Disponível em: $<$ http://www.un.org/en/peacekeeping/resources/statistics/factsheet.shtml $>$. Acesso em: 12 set. 2013.

. 2014. Monthly Summary of Contributors. New York, 31 May. Disponível em: $<$ http://www.un.org/en/peacekeeping/resources/statistics/factsheet.shtml>. Acesso em: 30 jul. 2014.

. 2008. Peacekeeping Operations Principles and Guidelines. New York: Department of Peacekeeping Operations/ Department of Field Support.

. S/Res/2098. 2013. New York, 28 Mar. Disponível em: <http://www.un.org/ en/ga/search/view_doc.asp?symbol=S/RES/2098\%282013\%29>. Acesso em 12 fev. 2014.

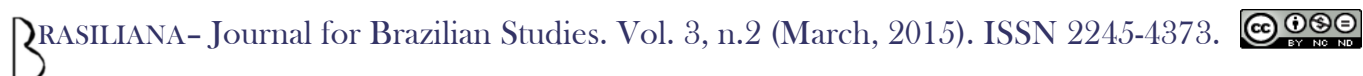

